\title{
Nociones de bienestar, desarrollo y Buen Vivir. Aproximaciones discursivas en las Universidades Interculturales de Chiapas y el Estado de México.
}

\author{
Notions of welfare, development and Buen Vivir. Discursive approaches in the \\ Intercultural Universities in Chiapas and the State of Mexico.
}

\author{
Zuzana Erdösová \\ Universidad Autónoma del Estado de México. \\ Contacto: zuzana.erdosova@gmail.com \\ Rafael Juárez Toledo \\ Universidad Autónoma del Estado de México. \\ Contacto: rjtoledo70@yahoo.com.mx
}

\begin{abstract}
Resumen
El modelo educativo intercultural de educación superior que se suscribió en México a partir del año 2004 contiene un discurso que propone la amplitud de las oportunidades competitivas y de desarrollo para la erradicación de la pobreza de las regiones étnicas de México; a este objetivo se somete también la noción del diálogo intercultural presente en el modelo educativo, el que adquiere una dimensión unilateral. Mediante una investigación testimonial y análisis del discurso se concluye que dicho pensamiento es reproducido con bastante fidelidad por los actores involucrados dentro del ámbito universitario intercultural, lo cual provoca una supeditación de la propuesta desarrollista sobre las perspectivas étnicas, como es el caso del Buen Vivir. El presente artículo hace referencia a los testimonios encontrados en dos de las Universidades Interculturales más emblemáticas: Estado de México y Chiapas.
\end{abstract}

Palabras clave: Desarrollo, Buen Vivir, universidad, interculturalidad, México.

\begin{abstract}
The Intercultural University educational model established in Mexico in 2004 constitutes a discourse which aims to provide the ethnic regions of Mexico with a range of competitive opportunities and development to eradicate poverty. These goals are impacted by the notion of intercultural dialogue present in the educational model, which is conceptualized as a one-sided process. Based on testimonies and discourse analysis, the article concludes that such a one-sided approach is faithfully reproduced by the Intercultural University agents, which causes the consequent subordination of ethnic perspectives, such as "Buen Vivir," to the dominant developmental ideology. This paper discusses the testimonies gathered in two emblematic Intercultural Universities located in the State of México and Chiapas.
\end{abstract}

Key words: Development, well-being, university, interculturalism, Mexico.

Zuzana Erdösová y Rafael Juárez Toledo,

Nociones de bienestar, desarrollo y Buen Vivir. Aproximaciones discursivas en las Universidades Interculturales de Chiapas y el Estado de México, Autoctonía. Revista de Ciencias Sociales e Historia, Vol. I, N² 2, Julio-Diciembre 2017, 209-223

ISSN 0719-8213 


\section{Introducción}

La Universidad Intercultural y/o Indígena en Latinoamérica dista de ser un fenómeno educativo homogéneo. En realidad se trata de una serie de modelos educativos que han ido emergiendo en esta región aproximadamente desde la década de los años 90 y que se posicionan contra las intenciones de simplemente incluir a los jóvenes indígenas en las estructuras universitarias existentes o convencionales. A rasgos generales, se trata de instituciones surgidas para atender las necesidades, demandas y propuestas de formación en educación superior de comunidades de más de una tradición cultural, en las cuales se integran y relacionan los modos de producción de conocimiento y de aprendizaje de varias tradiciones culturales (Mato, 2009). Desde que fue fundada la primera organización de este tipo en Nicaragua en 1996, han seguido decenas de iniciativas semejantes.

En general, la fundación de las Universidades Interculturales está motivada desde dos fuentes principales: algunas surgen en la periferia de las sociedades latinoamericanas dominantes por el impulso de los pueblos originarios y como tales se basan en argumentación ligada a la autonomía y la autodeterminación étnica; otras son fundadas por los gobiernos de los países, generalmente tienen rasgos de acción afirmativa que debe compensar la centenaria inequidad en el acceso de los indígenas a la educación superior y operan con el concepto de la "pertinencia educativa" que equivale a la adecuación curricular a las realidades culturales de los pueblos que las Universidades Interculturales atienden. La relación entre estas dos macroconcepciones educativas es conflictiva, ya que se enmarca en una negociación determinada por las relaciones de poder entre los grupos minoritarios y la sociedad mayoritaria en el campo del conocimiento (otorgamiento de acreditaciones, formulación de planes de estudio, etc.). Uno de los factores es que en el Convenio 169 de la OIT, documento de alta relevancia en el área de los derechos colectivos étnicos que ha sido firmado por una parte considerable de los países latinoamericanos, por un lado se otorga el derecho a los pueblos originarios a crear sus propias instituciones educativas, pero por otro lado, se establecen los mecanismos de control de los que deben disponer los estados (Mato, 2014: 21).

En México, que hoy es el país latinoamericano que más ha desarrollado este modelo universitario alternativo, la fundación de la Universidad
Intercultural en 2004 representó un momento importante dentro del contexto de las relaciones interétnicas. A través de este modelo educativo, el Estado mexicano asumió una postura actualizada hacia los grupos étnicos presentes en el país para involucrarlos en la toma de decisiones sobre las formas deseables del desarrollo en sus localidades. La gestión del nuevo modelo se encargó a la Coordinación General de Educación Intercultural y Bilingüe (CGEIB) que es un organismo de la Secretaría de Educación Pública (SEP). De esta manera, con las Universidades Interculturales en la actualidad culmina la historia moderna de la educación étnica en México, la que se enmarca en tres corrientes de pensamiento clave. Primero, en el pensamiento indigenista postrevolucionario, basado en la convicción de que es necesario asimilar a los pueblos originarios a la nación mexicana mestiza y crear una nueva raza (inicio del siglo XX). Segundo, desde los años 70, en el multiculturalismo neoliberal que aboga por la creación de indígenas-ciudadanos circunscritos al proyecto moderno-colonial y en cuyo marco "la diversidad en creciente lucha se convierte en un problema de gubernamentalidad para los Estados y encuentra como respuesta la integración" (Vargas-Moreno, 2016: 125). Tercero, en la vertiente interculturalista, la que reformula positivamente la aproximación hacia la diversidad cultural, antes vista como un problema por resolver, y crea la modalidad educativa Intercultural Bilingüe, diseñada como una educación con el protagonismo activo de los pueblos originarios (a partir de los años 90).

$\mathrm{Al}$ inicio del tercer milenio persiste el hilo que une los tres tipos de pensamiento, aunque en los discursos oficiales este hecho ha sido encubierto con conceptos "amistosos" hacia la diversidad cultural, como es precisamente el de la interculturalidad. De tal modo que la relación entre las poblaciones étnicas de México y el sistema educativo nacional de alguna manera sigue basándose en las ideas "neoindigenistas" que hoy ponen menor énfasis en la directa asimilación cultural de los "otros" y, en cambio, de acuerdo con la llamada de la globalización priorizan su inserción en el mercado (Korsbaek y Sámano, 2007).

En el contexto de lo anterior, el presente artículo propone evidenciar, a través de un estudio testimonial, la relación entre el discurso que contiene la teoría educativa de la Universidad Intercultural en México y el producido por los actores de dos Universidades selectas respecto a las nociones del 
desarrollo y bienestar! Lo anterior en el entendido de que uno de los principales resultados que debe provenir de dicho modelo educativo es la amplitud de las capacidades de inserción al desarrollo de las poblaciones indígenas atendidas, al mismo tiempo que se postula la aspiración interculturalista de entablar, en condiciones de equidad, un "diálogo de saberes" entre la ciencia moderna y los conocimientos $\mathrm{t}$ radicionales indígenas, vistos como dos sistemas epistémicos distintos pero de igual valor. Esta idea clave atraviesa la teoría educativa de la Universidad Intercultural, descrita a detalle en el manual publicado por CGEIB (véase Casillas y Santini, 2006). Lo anterior se traduce en dos propósitos fundamentales: 1) el de rescatar las culturas y lenguas originarias de México, vistas como entes culturales en proceso de erosión por la influencia de un entorno cada vez más globalizado, 2) el de detonar el desarrollo de las zonas marginadas indígenas del país. Estas metas ambiciosas están basadas en una visión específica de las categorías conceptuales nucleares que conforman la teoría educativa de la Universidad Intercultural, de las cuales en este artículo nos interesan específicamente las del desarrollo y bienestar.

Al hablar sobre el desarrollo de las regiones marginadas, las Universidades Interculturales inevitablemente entran en el campo de lo que implica la "calidad de vida" o "bienestar". Estas categorías son culturalmente determinadas porque lo que significa vivir con calidad según unos, en otro contexto cultural puede chocar con preferencias, necesidades y valores distintos. Por lo tanto, si la Universidad Intercultural pretende gestionar el desarrollo local a través de un diálogo de saberes fundamentado con valores interculturales, es de suponer que al menos en teoría se compromete a involucrar más de una lógica cultural en su reflexión e implementación del "bienestar". Pero dado el contexto ideológico neoindigenista en que se enmarcan las relaciones entre los grupos étnicos y el Estado mexicano, es probable que la realización de tal diálogo de saberes va a dificultarse, lo cual se reflejará en cierto tipo de formulaciones discursivas presentes dentro de teoría educativa de la Universidad Intercultural y también en los testimonios personales.

\section{Fundamentos del desarrollo}

La historia de la región latinoamericana refleja amplias posibilidades para interpretar las nociones del desarrollo con perspectivas multiculturales, incluso interculturales. La fuerte diversidad de grupos étnicos y la gran variedad de lenguas autóctonas han colocado un modo alternativo para la mayor adecuación a los contextos particulares en referencia a un desarrollo como un "hecho vivo y cambiante" (Soler et al., 2014: 21).

Sin embargo, la noción del desarrollo imperante, hoy día, no sólo en México, sino en gran parte de la región latinoamericana, proviene de la emulación desde los países denominados desarrollados, basada en una perspectiva convencional de tipo occidental. Ésta se dirige, sobre todo, a la búsqueda de la modernización y por ende ha otorgado especial relevancia a los criterios de política pública sujetos a la industrialización, la urbanización, la elevación de la competitividad en todas sus escalas y la amplitud de la productividad. Todo lo anterior ha obligado a la reestructuración de las bases internas, constitucionales, con el afán de crear mejores articulaciones de los países con el contexto mundial. Pero, estos cambios se han acompañado de fuertes reformas que obligan a las poblaciones a tener que ajustarse a una nueva manera de percibir el desarrollo individual. A este proceso Nederveen (2001) le había denominado westernization. En consideración a lo anterior, con un sentido crítico Escobar (en Peet y Hartwick, 2009) concibió que el modelo fuerte para evaluar el desarrollo había surgido como resultado del asentamiento del eurocentrismo.

La manifestación social y cultural desde los contextos locales, específicamente de carácter indígena ha generado una fuerte resistencia ante los significados desarrollistas que provienen de la esfera pública institucionalizada. Con todo, se ha logrado crear un nuevo entendido acerca del desarrollo que ubica en el centro al ser humano, lo que ha configurado nueva agenda para el desarrollo con un sentido humanista, ecológico y de amplitud en la cooperación internacional. Esto ha tendido a incluir a todos los espacios territoriales posibles, aunque se ha llevado desde un planteamiento de políticas globalizadas.

Con esta perspectiva proliferó el discurso asociado con el empoderamiento y la mayor capacidad de gestión de los actores locales. América Latina se ha empapado de los discursos que pretenden ampliar la fórmula del desarrollo hacia una visión ética que se fundamenta en la defensa de todo aquello que 
se considera necesario para organizar un sistema de bienestar con sentido humano2. La mayor relevancia de estas propuestas más allá de su base axiomática y de las directrices bajo las que operan, radica en la promoción gestora que atribuyen a los individuos y las colectividades, de manera que han buscado otorgar mayor peso a la participación de los territorios, y su población, en el diseño de sus propias estrategias de desarrollo. Pero por otro lado, se observa la carencia de mecanismos eficientes para que esta oportunidad de autogestoría, en efecto, dé muestras de las posibilidades de desarrollo en los contextos locales y regionales, como sucede en el caso de las poblaciones indígenas en México.

La situación que vive el desempeño del desarrollo en la actualidad se mantiene dentro de un contexto de reinterpretaciones institucionalizadas y legitimadas desde los acuerdos internacionales y las cumbres mundiales. Lo que a nuestro parecer ha desembocado en una visión parcial del desarrollo mediante una lógica dominante que, si bien asume la ética y el humanismo como propuesta, en la práctica ha hecho referencia a la simple implementación de medidas de escala nacional bajo el discurso de la amplitud de las capacidades y oportunidades para los grupos desfavorecidos. Se ha fomentado la incorporación de un discurso intertemporal de carácter sostenible pero ajeno a la historia específica de las poblaciones, es decir, no se logrado promover la diferenciación funcional de cada lugar, y por ende el pleno respeto al desarrollo autocentrado.

De manera específica resulta conveniente abordar la cuestión del bienestar desde perspectivas acuñadas en otras tradiciones culturales o influidas por ellas. En Latinoamérica se trata ante todo del llamado Buen Vivir que equivale a una serie de corrientes de pensamiento que se nutren de las cosmovisiones de los pueblos originarios amerindios y que, en su totalidad, se oponen a la visión económica neoliberal, abogando por sistemas basados en la equidad social y/o sostenibilidad ambiental. Aquí, como señala Hidalgo-Capitán (2014: 26), se acaban los consensos y la problemática se desborda en una gama de vertientes, dentro de las cuales las ideas indígenas que conforman el Buen Vivir son retomadas por diferentes actores y para múltiples fines. Algunas han sido convertidas en propuestas económicas y políticas; de éstas, algunas son alternativas a las neoliberales y otras meramente aprovechan el término "Buen Vivir" en su retórica para encubrir el rumbo neoliberal persistente (Acosta, 2014: 49). Dentro de dichas vertientes existen aproximaciones diferenciadas a la problemática del "desarrollo" y "bienestar", como se detalla en la siguiente tabla:

\begin{tabular}{|c|c|c|c|}
\hline Vertiente & $\begin{array}{l}\text { Autodenomi- } \\
\text { nación }\end{array}$ & $\begin{array}{c}\text { Origen } \\
\text { epistémico }\end{array}$ & Concepción del bienestar \\
\hline Socialista & $\begin{array}{l}\text { Buen Vivir, } \\
\text { Vivir Bien }\end{array}$ & $\begin{array}{l}\text { Occidental } \\
\text { (propuesta } \\
\text { racional de } \\
\text { transforma- } \\
\text { ción social) }\end{array}$ & $\begin{array}{l}\text { Proyecto de un nuevo sistema socioeconómico post- } \\
\text { capitalista basado en el neomarxismo y entendido como } \\
\text { una variante andina del socialismo; gestión estatal y } \\
\text { extractivismo como modelo de desarrollo; satisfacción de } \\
\text { necesidades, calidad de vida; opuesto al neoliberalismo y } \\
\text { capitalismo. }\end{array}$ \\
\hline Ecologista & Buen Vivir & $\begin{array}{l}\text { Originario } \\
\text { amerindio y } \\
\text { occidental } \\
\text { (pensamiento } \\
\text { constructi- } \\
\text { vista } \\
\text { postmoderno) }\end{array}$ & $\begin{array}{l}\text { Apropiación de un concepto indígena para la construcción } \\
\text { participativa del bienestar; rechazo del concepto de } \\
\text { desarrollo que lleva implícito el metarrelato universalizante } \\
\text { occidental, propuesta de un camino postdesarrollista y } \\
\text { postmoderno para la preservación de la naturaleza con } \\
\text { amplia participación social (grupos étnicos, feministas, } \\
\text { ecologistas, etc.). }\end{array}$ \\
\hline Indigenista & $\begin{array}{l}\text { Vida en Plenitud } \\
\text { (Suma Qamaña, } \\
\text { Sumak Kawsay, } \\
\text { etc.) }\end{array}$ & $\begin{array}{l}\text { Originario } \\
\text { amerindio }\end{array}$ & $\begin{array}{l}\text { Proyecto de autodeterminación de los pueblos indígenas, } \\
\text { usado por los movimientos indígenas boliviano, } \\
\text { ecuatoriano y peruano; contiene elementos espirituales } \\
\text { andinos; ante la ausencia del concepto de desarrollo en la } \\
\text { cosmovisión andina se postula un concepto alternativo; } \\
\text { economía autosuficiente, comunitaria, solidaria, equitativa } \\
\text { y sostenible. }\end{array}$ \\
\hline
\end{tabular}

Tabla 1. Vertientes del debate sobre el Buen Vivir. Compilación con base en Hidalgo-Capitán (2014) 
El debate heterogéneo sobre el Buen Vivir es un antecedente importante para el análisis del discurso que surge alrededor de la problemática del desarrollo en Latinoamérica, porque constituye un buen marco comparativo al analizar las bases sobre las que se construyen los modelos educativos interculturales. Sobre todo llama la atención que los actos discursivos alrededor del Buen Vivir estén posicionados en posturas culturalmente céntricas:

Dichos debates podrían ser más fructíferos si sus participantes hicieran el esfuerzo de comprender las aportaciones de sus interlocutores atendiendo al marco epistemológico al que pertenecen éstos, y no valorando dichas aportaciones a partir del marco en el que se sitúa cada uno (HidalgoCapitán 2014, 35).

Esto afecta particularmente el concepto de la "interculturalidad", el que está propenso a ser objeto de diversas manipulaciones discursivas debido a intereses subyacentes y que puede usarse para apoyar diferentes perspectivas surgidas en torno al bienestar humano. En otras palabras, el desarrollo que se planifique e implemente en nombre de la interculturalidad bien puede servir para encubrir las relaciones de poder imperantes entre los que deciden sobre la orientación del desarrollo y los atendidos por sus acciones.

\section{Metodología}

En 2017, son doce las Universidades Interculturales en México, de las cuales se seleccionaron dos desde el criterio de representatividad: la Universidad Intercultural del Estado de México (UIEM) y la Universidad Intercultural de Chiapas (UNICH). Ambas son instituciones pioneras del modelo educativo en cuestión; así también, las dos se integran dentro de dos entidades que se reconocen por su fuerte tradición étnica y diversidad de pueblos indígenas. El análisis de discurso se basó en reconocimientos y observación directa dentro y en el entorno de estas Universidades, otra parte se sustentó mediante la desagregación de los documentos y datos oficiales, pero la mayor fortaleza se tuvo en una serie de entrevistas a profundidad, 28 en total, que arrojó la evidencia testimonial para contrastar con los planteamientos derivados del diseño propio de la educación intercultural a nivel superior. Resultó relevante acudir a diferentes actores institucionales. En primer lugar, a los directivos (rectores) y los trabajadores académicos, los que son al mismo tiempo receptores y transmisores de la teoría educativa. En el caso de los segundos se seleccionó a los encargados de la llamada Vinculación Comunitaria, la que representa uno de los ejes transversales del modelo educativo de la Universidad Intercultural y presupone que la construcción del conocimiento en los espacios académicos interculturales (tanto en los procesos de enseñanza como en la investigación científica) debe hacerse desde y para las comunidades locales. De manera complementaria, se analiza la visión de los egresados de las Universidades seleccionadas, los que supuestamente traducen los planteamientos interculturales teóricos en prácticas contidianas en el marco de sus vidas profesionales. De tal modo que el discurso analizado se manifiesta a tres niveles: 1) el oficial (creadores y gestores del modelo educativo de la SEP/CGEIB), 2) el institucional (directivos, trabajadores académicos) y 3) el de los egresados.

\section{La concepción del desarrollo y bienestar en el discurso sobre y desde la Universidad Intercultural en México}

El primer nivel discursivo por analizar equivale a la teoría educativa que contiene la concepción general de la Universidad Intercultural, su axiología, metas, etc. Se encuentra plasmada en el texto base anteriormente mencionado, titulado Universidad Intercultural, modelo educativo (Casillas y Santini, 2006). En este manual se expone la idea central que consiste en señalar la urgencia de impulsar una mayor sensibilidad entre la ciudadanía mexicana hacia el potencial y aportación de los pueblos originarios al desarrollo nacional. Dicha sensibilidad forma parte de la interculturalidad, entendida como una relación respetuosa y dialógica entre las culturas en contacto para la paz sociali; ; para construirla, el diálogo de saberes es el mecanismo idóneo. Sin embargo, en la teoría educativa al mismo tiempo se declara que "la ausencia de oportunidades de desarrollo para diversos sectores de la población provocó marginación y desplazamiento, y agudizó la desigualdad social" (Casillas y Santini, 2006: 19), con lo que se cancela la idea anterior al priorizar los modelos de desarrollo emitidos unilateralamente desde la esfera institucional oficial hacia las zonas étnicas marginadas. Esta contradicción discursiva puede resumirse en forma de la siguiente pregunta: 
¿Diálogo intercultural en condiciones de igualdad entre los diferentes tipos de conocimientos, o atención a los problemas diagnosticados desde fuera de las comunidades indígenas? La pregunta no se coloca con la pretensión de obligar al lector a elegir moralmente entre A y B, sino para aclarar el hecho de que la base discursiva de la teoría educativa intercultural resulta inconsecuente, lo que posiblemente pueda perjudicar el funcionamiento práctico del modelo educativo y el cumplimiento de sus objetivos (para contestar esta hipótesis habría que realizar una investigación aparte).

Un hecho fácilmente observable es que la teoría educativa suele situar las nuevas Universidades Interculturales en ambientes rurales y de alta presencia étnica con el argumento de que es necesario disminuir la inequidad entre los alumnos indígenas y los mestizos en el acceso a la educación superior, entendida como el puente hacia mejores entándares de vida. Esta estrategia por sí misma resulta muy relevante. El conflicto consiste en el riesgo de perjudicar el equilibrio dentro del "diálogo de saberes" al reducir a las comunidades indígenas en meros receptores pasivos de una política educativa oficial, o sea, orientar el modelo educativo hacia estas comunidades sin invitarlas a participar en la construcción de un nuevo modelo de desarrollo compatible con sus racionalidades culturales. En la teoría educativa hay varios momentos emblemáticos que reflejan la postura mencionada: la oferta académica de las nuevas instituciones debe "dar un enfoque que privilegie esencialmente la atención de necesidades de desarrollo de la población indígena (...) y preparar a jóvenes y adultos indígenas para que sean agentes activos de transformación de su entorno" (Casillas y Santini, 2006: 22, 132). A nivel del lenguaje, son las palabras "atención" y "preparar" que revelan la actitud asistencialista y paternalista.

Por último, cabe señalar que para atenuar las posibles acusaciones de discriminación positiva e incluso de segregación étnica, en el discurso oficial de la Universidad Intercultural se insiste en la presencia de los no indígenas en los salones y se nombra el modelo educativo "intercultural"; por cierto, trazando fronteras más imaginarias que reales entre lo "indígena" y lo "mestizo".

Ahora bien, con base en lo anterior planteamos el siguiente cuestionamiento: ¿Cómo se reproduce la visión del bienestar que contiene la teoría educativa en los espacios universitarios locales y qué posiciones críticas posiblemente existen? El análisis que sigue se desdobla en dos niveles: primero se estudian las producciones discursivas de los actores institucionales (rectores, trabajadores académicos encargados de la Vinculación Comunitaria) y después las de los exalumnos.

Respecto al nivel institucional, en la Tabla 2 se reúnen las ideas principales sobre lo que significa el desarrollo para los actores entrevistados de la UNICH y la UIEM.

\begin{tabular}{|c|c|}
\hline $\begin{array}{l}\text { Idea presente en el } \\
\text { discurso }\end{array}$ & Testimonios particulares \\
\hline $\begin{array}{l}\text { Desarrollo equivale } \\
\text { al "bienestar" en } \\
\text { términos de una } \\
\text { mejora social y } \\
\text { económica, se } \\
\text { define con base en } \\
\text { las necesidades de } \\
\text { las comunidades } \\
\text { locales, fusionando } \\
\text { sus conocimientos } \\
\text { tradicionales con } \\
\text { los modernos } \\
\text { tecnológico- } \\
\text { científicos y se } \\
\text { logra con el } \\
\text { desempeño laboral } \\
\text { de los egresados } \\
\text { de las } \\
\text { Universidades } \\
\text { Interculturales. }\end{array}$ & $\begin{array}{l}\text { "Lo que nosotros estamos entendiendo es el bienestar de las comunidades, cómo las } \\
\text { comunidades ven su buen vivir. Eso es lo que entenderíamos como el concepto } \\
\text { ambiguo del desarrollo, el buen vivir o el mejor vivir de las comunidades." (entr. UIEM- } \\
\text { Rector) } \\
\text { "Qué es nuestra razón de ser en la Universidad, es formar profesionales de alta calidad } \\
\text { en razón de la carrera específica... que retornen a su comunidad. Y que en este retorno } \\
\text { y con las herramientas que la Universidad les provee puedan generar, desde y con las } \\
\text { comunidades, desarrollo económico y progreso social. Ésta es la misión de la } \\
\text { Universidad en razón de la formación de estos nuevos profesionales, entendido el } \\
\text { desarrollo como el bien colectivo." (entr. UNICH-Rector) } \\
\text { "Partir de los conocimientos de la gente, de su experiencia, y de sus necesidades } \\
\text { también, e integrar con el conocimiento científico que se está generando en la } \\
\text { Universidad... que les dé ese vivir mejor, desde su visión, desde sus necesidades, y } \\
\text { desde apropiaciones e innovaciones que se van desarrollando a nivel tecnológico y a } \\
\text { nivel científico para que ellos puedan decir "estoy bien"." (entr. UIEM-trabajador } \\
\text { Vinculación Comunitaria 1) } \\
\text { "Se empezó a decidir sobre las economías solidarias y las economías locales. (..) Les } \\
\text { ofrecemos la idea a todos: a los productores, a los artesanos, para que ellos entren en } \\
\text { la formalidad y que desde esta formalidad puedan tener un crecimiento económico." } \\
\text { (entr. UIEM-trabajador Vinculación Comunitaria 2) }\end{array}$ \\
\hline
\end{tabular}




\begin{tabular}{|l|l|}
\hline $\begin{array}{l}\text { Desarrollo equivale } \\
\text { a eliminar la } \\
\text { marginación. }\end{array}$ & $\begin{array}{l}\text { "Nos falta hacer mucho trabajo en cuestión al egresado emprendedor, de hecho ése es } \\
\text { el ideal de la Universidad, que deben de hacer proyectos de desarrollo en sus mismas } \\
\text { comunidades, que se supone que es el origen de las Universidades Interculturales que } \\
\text { se van ubicando en espacios de alta marginación. Y que precisamente, el egresado } \\
\text { debería hacer impacto en esta marginación." (entr. UIEM-trabajador Vinculación } \\
\text { Comunitaria 3) }\end{array}$ \\
\hline $\begin{array}{l}\text { Desarrollo equivale } \\
\text { a una competencia } \\
\text { desaprovechada } \\
\text { con los países } \\
\text { desarrolla-dos en el que tiene tanta riqueza y nos pavoneamos de que somos como el tercer o } \\
\text { marco de la } \\
\text { globalización. }\end{array}$ & $\begin{array}{l}\text { quinto lugar en la biodiversidad del mundo, pero no la estamos aprovechando, ino } \\
\text { del mundo y sólo estamos viendo qué pasa. Entonces creo que necesitamos movernos. } \\
\text { Tenemos que ir al ritmo del mundo, al ritmo de las nuevas condiciones que se } \\
\text { presentan y que eso nos pone un reto muy grande, hay que ir evolucionando para } \\
\text { adaptarnos al mundo actual, no sólo ir cambiando por cambiar." (entr.UNICH-trabajador } \\
\text { Vinculación Comunitaria 1) }\end{array}$ \\
\hline
\end{tabular}

Tabla 2. Definiciones del desarrollo y bienestar en el discurso institucionalde la UNICH y UIEM (elaboración propia).

Podemos ver que los conceptos que rigen el discurso institucional de la UNICH y la UIEM son los siguientes: a) formas de nombrar la calidad de vida: bienestar, buen vivir, vivir mejor, desarrollo (económico, sustentable, educativo), progreso social, crecimiento económico, 2) tipos de economías: locales, solidarias, 3) circunstancias negativas: rezago social, marginación, necesidades por atender, 4) mecanismos para alcanzar el bienestar: avanzar, evolucionar, mejorar, oportunidades, innovación, 5) agentes y factores para alcanzar el bienestar: profesional, especialista, experto, éxito, calidad, 6) mecanismos sociales concretos para alcanzar el bienestar: relaciones de mercado, empresas, gobierno, instituciones, alianzas estratégicas, negocios sociales, proyectos productivos, modelo de incubación, capital, capacitación. Se trata de un lenguaje conceptual donde predominan las ideas propias del imaginario occidental moderno: evolución lineal (progreso), actitud econocéntrica hacia el bienestar, lógica de competición para el éxito individual. Estos ejes espistémicos en gran medida no son compatibles con la cosmovisión mesoamericana (basada en la percepción holística, cíclica y colectiva de la existencia humana), un hecho que influye sobre cualquier debate acerca del desarrollo que pueda transcurrir entre las instancias oficiales del Estado y las comunidades indígenas y requiere de una aproximación intercultural abierta y sensible.

Respecto alo recién dicho, en el discurso institucional detectado en la UNICH y la UIEM por un lado se coloca énfasis en las necesidades particulares de cada localidad, sus valores y conocimientos propios, y en la participación de las comunidades en la toma de decisiones sobre lo que implica la "vida buena". Pero a pesar de tales declaraciones, llama la atención que todos los actores entrevistados acudan a un lenguaje conceptual que no permite pensar el desarrollo en términos diametralmente diferentes de los occidentales. Esta visión unilateral pone en tela de juicio la autenticidad del diálogo de saberes en que se basa la teoría educativa, ahogando las menciones ocasionales de los conceptos que podríamos llamar alternativos (por ejemplo, el Buen Vivir) en un discurso basado en la lógica del execedente y del crecimiento económico. De acuerdo con esta lógica, los entrevistados son conscientes de una serie de condiciones necesarias para que el bienestar en el sentido expuesto pueda alcanzarse, las mismas que se desglosan en la Tabla 3: 
Z. Erdösová y R. Juárez, Nociones de bienestar, desarrollo y Buen Vivir.

Autoctonía. Revista de Ciencias Sociales e Historia, Vol. I, N²

Criterios de desarrollo comunitario en el discurso institucional

Idea presente en Testimonios particulares

el discurso

I. Cooperación

con los

organismos

gubernamentales

y dependencia de

su concepción

del desarrollo.

"Los proyectos deben ir alineados a lo que es el Plan Nacional de Desarrollo para los Pueblos Indígenas y lo que es el Plan Sectorial de Educación. Porque dicen: "¿A qué lineamientos se van acordes para lo que es la educación y para el desarrollo de los pueblos indígenas?" Así que no es que yo lo propongo y lo hago. Tienes que buscarle una justificación muy precisa para que ellos te puedan apoyar. Dentro del objetivo que establece el Plan de Desarrollo tú vas a hacer tu propuesta, no es porque yo quise." (entr. UNICH-trabajador Vinculación Comunitaria 2)

"Surgimos... con la perspectiva de formación de negocios sociales y bajo el modelo de incubación que estaba apoyando la Federación y el estado. (...) Como incubadora hemos apoyado a artesanos, a agricultores, a productores, y en lo que más nos hemos consolidado es en las alizanzas estratégicas con cámaras... tenemos ahorita el apoyo del gobierno del estado a través de instituciones que apoyan el crecimiento económico (...) Lo que hice es no involucrar solamente a gobierno, empresas, instituciones educativas, sino también a las comunidades, así estamos formando una cuarta hélice. La idea es ganar ganar para las propias comunidades y a la par ganar ganar a la Universidad y ganar ganar para el gobierno." (entr. UIEM-trabajador Vinculación Comunitaria 2)

"Cuando nosotros empezamos, no teníamos todo un planteamiento teórico y metodológico. Encontramos de entrada una institución que te dice que tienes que tener un plan de mercadotecnia etcétera, entonces decimos: "Bueno, la propuesta son pequeños productores... Lo primero que decimos es, para autosuficiencia, para autoconsumo. $Y$ eso empezó a cuestionarse. Eso hacía que un proyecto no podía pasar, porque "es para que puedan vender sus cosas"." (entr. UIEM-trabajador Vinculación Comunitaria 1)

II. Vínculo Universidad Intercultural y las comunidades indígenas que presupone la acción participativa de las últimas.

"...que en este retorno y con las herramientas que la Universidad les provee puedan generar, desde y con las comunidades, desarrollo económico y progreso social. (...) Desde este conjunto valoral que define a la comunidad, tienen el elemento central de la solidaridad y de la producción en colectivo. El interés, entonces, del desarrollo visto desde la Universidad es el desarrollo en colectivo en beneficio del orden social... (...) Nosotros estamos firmando un convenio con Cuba para trabajar un proyecto que tiene que ver con el desarrollo participativo y que no es otra cosa más que impulsar el desarrollo desde las comunidades con un esquema participativo, integral, incluyente, que se sienta empoderada la gente de la comunidad en su propio bienestar." (entr. UNICH-Rector)

"A partir del trabajo participativo con las comunidades, las comunidades definen cuáles son sus problemáticas, y entonces atacamos las problemáticas de acuerdo a las necesidades de las propias comunidades." (entr. UIEM-Rector)

III. Actitud paternalista hacia los culturalmente "otros" y socialmente rezagados.

"Ese trabajo de acercarse a la comunidad, de conocer su forma de ser y de qué forma tú podrás ayudarlos..." (entr. UNICH-trabajador Vinculación Comunitaria 2)

"Hay a veces cuestiones en cuanto a algún indígena que, a pesar de que se sabe necesitado, no acepta la ayuda." (entr. UIEM-trabajador Vinculación Comunitaria 3)

"Desde el primer semestre, hay que tener un vínculo con las comunidades, principalmente de rezago social, de marginación, indígenas. (...) De llegar a las comunidades y no imponer sino tratar de adaptar culturalmente cómo podemos ayudar a las comunidades." (entr. UNICH-trabajador Vinculación Comunitaria 1)

IV. Inculcación de la lógica emprendedora a los actores comunitarios. Nosotros hemos brindado capacitación en materia de la formación de negocios. Ahorita, el modelo que nosotros traemos, es que justamente al relacionar todas las instituciones, prácticamente les ofrecemos la idea a todos: a los productores, a los artesanos, para que ellos entren en la formalidad y que desde esta formalidad puedan tener un crecimiento económico." (entr. UIEM-trabajador Vinculación Comunitaria 2)

"Sí metimos el término de empresa pero estamos con pequeños productores. (...) Hemos venido trabajando desde el Tianguis, desde hacer proyectos productivos, agropecuarios, cómo con la gente construir este espacio donde ellos, desde lo que tienen, puedan 


\begin{tabular}{|c|c|}
\hline & $\begin{array}{l}\text { avanzar. No esperar que el apoyo venga de las instituciones de desarrollo. (...) Ahora } \\
\text { algunos invernaderos se están rompiendo. Casi están esperando que haya otro apoyo... } \\
\text { ¿Cómo dar mantenimiento desde tus propios recursos? Desde que si vas haciendo } \\
\text { pequeño ahorro, pueden como grupo conseguir capital, hacer crecer un fondo que te } \\
\text { permite resolver y seguir con tu producción y avanzar." (entr. UIEM-trabajador Vinculación } \\
\text { Comunitaria 1) } \\
\text { "Chiapas está en el último lugar en analfabetismo, entonces tenemos un grave problema... } \\
\text { y es una deficiencia que se viene arrastrando, que tratando en estas nuevas políticas de } \\
\text { lograr impulsar ese desarrollo educativo y el que todos tengan las mismas oportunidades, } \\
\text { pues te tienes que topar con que tienes que regularizar a la gente. (...) Digamos que llegara } \\
\text { un día en que toda nuestra población indígena sea alfabeta y que pueda manejar una } \\
\text { máquina de este milenio. Y que pueda tener relaciones de mercado con sus productos } \\
\text { para vender hasta otros países. Pues ya le hicimos." (entr. UNICH-trabajador Vinculación } \\
\text { Comunitaria 1) }\end{array}$ \\
\hline $\begin{array}{l}\text { V. Nivelación } \\
\text { valorativa de los } \\
\text { alumnos de las } \\
\text { Universidades } \\
\text { Interculturales } \\
\text { para convertirlos } \\
\text { en agentes de } \\
\text { desarrollo en las } \\
\text { comunidades. }\end{array}$ & $\begin{array}{l}\text { "Ésta es la pretensión: el especialista en desarrollo sustentable que regrese a su } \\
\text { comunidad que desde allá detone proyectos productivos, busque financiamientos en las } \\
\text { instituciones gubernamentales o fuera de ellas y pueda generar proyectos de desarrollo } \\
\text { comunitario." (entr. UNICH-Rector) } \\
\text { "Todos los estudiantes deben tener los mismos métodos, técnicas, análisis, valores, saber } \\
\text { hacer y saber conocer para poder acercarse a las comunidades, y con alto sentido de } \\
\text { responsabilidad." (entr. UNICH-trabajador Vinculación Comunitaria 1) } \\
\text { "Un egresado de Desarrollo Sustentable... tiene la capacidad de ubicar las necesidades, las } \\
\text { especializaciones, las innovaciones, para poder conectar en un trabajo en comunidad con } \\
\text { la gente, no exactamente que sea experto pero tiene esa visión para poder en ese aspecto } \\
\text { técnico, social y económico, puede hacer el desarrollo." (entr. UIEM-trabajador Vinculación } \\
\text { Comunitaria 1) }\end{array}$ \\
\hline
\end{tabular}

Tabla 3. Criterios de desarrollo comunitario en el discurso institucional en la UNICH y UIEM (elaboración propia).

Sintetizando los datos, puede observarse que los entrevistados comparten aproximadamente la misma lógica argumentativa, la que se divide entre cinco puntos clave que están relacionados pero no siempre mutuamente coherentes. Los testimonios citados en el marco del punto I) dejan claro que, por ejemplo, en las Universidades Interculturales no existe la libertad de definir los proyectos de desarrollo desde otras racionalidades que la oficial del Estado, ya que la concepción del bienestar debe atenerse estrictamente a la del Plan Nacional de Desarrollo vigente. De tal modo que un proyecto enfocado por ejemplo en la autosuficiencia alimenticia de una localidad no encuentra apoyo en las instancias oficiales, las que priorizan fortalecer la inserción de la comunidad en el mercado y los procesos de compra-venta. A este hecho le contradice el punto II) en que se presenta a las Universidades Interculturales como instituciones encargadas de realizar un diálogo de saberes igualitario entre los agentes étnicos locales y el Estado (representado por la Universidad), aparentemente sin discriminar sus conocimientos tradicionales, experiencias y necesidades particulares. La mayoría de los entrevistados caen en esta contradicción discursiva, aparentemente sin notarla, con la excepción del siguiente testimonio crítico:

Toda esa parte del conocimiento de la gente, de su cultura y de forma de organización, no hemos logrado integrarlo realmente en la parte de producción como gente externa que venimos. Veo como allá, por ejemplo, retoman esa Tierra, planeta, como parte sagrada... muchas veces vemos en los invernaderos el collar de flores porque dentro de la cultura ellos agradecen la siembra con pedir para que haya buena cosecha... Pero el trabajo de integrar esa parte de su relación con la tierra y su cosmovisión en lo que es la producción... lo que podría permitir también una mejor organización de la gente, tanto a 
nivel familiar como a nivel comunitario, yo siento que falta hacer (entr. UIEM-trabajador de Vinculación Comunitaria 1).

Siguiendo el hilo del discurso, en los puntos III) y IV) los entrevistados hablan desde una posición paternalista sobre las comunidades indígenas, situándolas en una posición pasiva respecto a las Universidades Interculturales que aportan propuestas para el desarrollo local y capacitan a los actores comunitarios en el pensamiento emprendedor. El lenguaje empleado para estos fines suele utilizar eufemismos, tales como "rezago social" o "marginación", para referirse a lo considerado como "subdesarrollo". Finalmente, en el punto V) se presenta a los alumnos que se están formando en las Universidades Interculturales como facilitadores del desarrollo e intermediarios entre las comunidades y el Estado, dotados de un pensamiento que integra los cuatro puntos anteriores.

Un hecho de interés es que dentro del discurso institucional se recurra al tema del Buen Vivir. Es donde podemos notar la mayor autonomía discursiva por parte de los actores institucionales tanto en la UNICH como en la UIEM, ya que la teoría educativa de la Universidad Intercultural hace caso omiso del Buen Vivir. Pero al mismo tiempo es indiscutible que en la América Latina actual, el Buen Vivir es una orientación intelectual que penetra considerablemente en los discursos dedicados al bienestar y a las relaciones interculturales. Aunque en México no existe un debate sobre el Buen Vivir tan consolidado como por ejemplo en Ecuador o Bolivia, la cosmovisión mesoamericana sí contiene una concepción milenaria de "vivir bien" (por ejemplo, el lekil kuxlejal del pueblo mayense tzotzil de la zona en que está ubicada la UNICH). Es probable que el contexto latinoamericano obligue a los actores involucrados en el modelo educativo de la Universidad Intercultural a tomar en cuenta el Buen Vivir como una propuesta filosófica y política emergente, reaccionar y tomar una postura frente a ella, pero sobre todo incorporarla de alguna manera en sus propios discursos para mantenerlos actualizados.

El uso del Buen Vivir como referente es notorio sobre todo en el habla de los directivos de la UNICH y la UIEM. La labor científica realizada en estas dos Universidades pone en evidencia el esfuerzo por entender la categoría del Buen Vivir a través de la investigación y desde las culturas originarias de las regiones respectivas (véase Sartorello et al., 2012). Sin embargo, se nota que a los entrevistados, la problemática del Buen Vivir les resulta mucho más opaca que la del desarrollo en el sentido moderno, como se aprecia en la Tabla 4:

\begin{tabular}{|c|l|}
\hline $\begin{array}{c}\text { Idea presente en } \\
\text { el discurso }\end{array}$ & \multicolumn{1}{c|}{ Testimonios particulares } \\
\hline $\begin{array}{c}\text { Definición } \\
\text { personal del Buen } \\
\text { Vivir }\end{array}$ & $\begin{array}{l}\text { "El querer vivir mejor es congénito, yo digo, al ser humano. En la literatura lo vamos a } \\
\text { encontrar desde los griegos, desde la civitas se planteaba "la buena vida" o la "vida } \\
\text { buena" como decían los greco-romanos como propósito de la polis. En Bolivia se habla de } \\
\text { la "buena vida" y en el caso de Chiapas se ha localizado un concepto que se maneja en } \\
\text { tzotzil que es el kuxlejal cuya traducción literal es el "buen vivir". Y lo que detona es la } \\
\text { pretensión de la comunidad, de la familia, del ser humano, de acceder a mejor estándares } \\
\text { de vida." (entr. UNICH-Rector) }\end{array}$ \\
& $\begin{array}{l}\text { "El desarrollo es un concepto ambiguo, tiene toda una problemática conceptual. Lo que } \\
\text { nosotros estamos entendiendo es el bienestar de las comunidades, cómo las } \\
\text { comunidades ven su buen vivir. Entonces, a partir del trabajo participativo con las } \\
\text { comunidades, las comunidades definen cuáles son sus problemáticas, y entonces } \\
\text { atacamos las problemáticas de acuerdo a las necesidades de las propias comunidades. } \\
\text { Eso es lo que entenderíamos como el concepto ambiguo del desarrollo, el buen vivir o el } \\
\text { mejor vivir de las comunidades. (el mejor vivir) sería el sinónimo, tener una vida buena." } \\
\text { (entr. UlEM-Rector) }\end{array}$ \\
\hline
\end{tabular}




\begin{tabular}{|c|c|}
\hline $\begin{array}{l}\text { Relación Buen } \\
\quad \text { Vivir- } \\
\text { interculturalidad }\end{array}$ & $\begin{array}{l}\text { "La interculturalidad, nosotros la entendemos como primero el reconocimiento de la } \\
\text { diversidad existente, entendida, además, como un derecho, el poder ser cómo soy. Pero al } \\
\text { mismo tiempo, la interculturalidad la entendemos como el privilegio del diálogo como el } \\
\text { instrumento básico entre diferentes para construir acuerdos. Y como objetivo central, el } \\
\text { que vivamos en armonía." (entr. UNICH-Rector) } \\
\text { "La interculturalidad es el entendimiento, el diálogo y el puente entre las diversas formas } \\
\text { culturales de ver su bienestar, sus tradiciones, su cultura, su medicina tradicional, etc. } \\
\text { Entonces, si nosotros estamos buscando con este enfoque intercultural ver el buen vivir } \\
\text { en una comunidad, no va a ser el buen vivir de otra comunidad con otro concepto cultural. } \\
\text { (...) La interculturalidad es el diálogo, la capacidad de entender estas diferencias, de } \\
\text { especificamente en el desarrollo, del buen vivir, hay conceptos diferentes." (entr. UIEM- } \\
\text { Rector) }\end{array}$ \\
\hline $\begin{array}{c}\text { Diferencias } \\
\text { culturales } \\
\text { percibidas en las } \\
\text { nociones del } \\
\text { desarrollo }\end{array}$ & $\begin{array}{l}\text { "En las comunidades, el buen vivir es la vida armónica, además, el respeto a los mayores } \\
\text { en la vieja tradición de muchas culturas, de los sabios, todavía en muchas de nuestras } \\
\text { comunidades, el líder de la comunidad, el que ocupa el cargo, es el sabio de la } \\
\text { comunidad. (...) Ocupar un cargo en la comunidad no se liga a lo que vas a ganar. Está } \\
\text { relacionado con quien brinda servicios a la comunidad. Tiene mayor honor el que más } \\
\text { servicios da a la comunidad. Y ésta es la lógica con la cual se mueven nuestras } \\
\text { comunidades, y yo digo, en el mundo mestizo deberíamos aprender o reaprender lo que } \\
\text { todavía tienen estas comunidades antes de que lo perdamos del todo." (entr. UNICH- } \\
\text { Rector) } \\
\text { "El buen vivir siempre se ha trabajado en las comunidades. Normalmente, los maestros } \\
\text { cuando llegan no entienden bien el concepto porque vienen desde universidades con una } \\
\text { visión anglosajona donde se entiende el desarrollo como progreso económico y } \\
\text { crecimiento económico y es difícil quitarles el concepto pero ya que empiezan a trabajar } \\
\text { con y para las comunidades, pues empiezan a entender el concepto de manera más } \\
\text { intuitiva que teórico-conceptual." (entr. UIEM-Rector) }\end{array}$ \\
\hline $\begin{array}{c}\text { Involucramiento } \\
\text { de las nociones } \\
\text { del Buen Vivir } \\
\text { dentro de la } \\
\text { Universidad } \\
\text { Intercultural }\end{array}$ & $\begin{array}{l}\text { "Desde la lógica indígena, particularmente tzotzil, la Universidad con uno de los cuerpos } \\
\text { académicos aquí integrados realizó una investigación en las comunidades y de allí se } \\
\text { genera este concepto, de allí que se incorpora no sólo a Medicina (Intercultural), en todas } \\
\text { las carreras prácticamente está inserto ya el planteamiento del concepto del buen vivir } \\
\text { como una categoría de análisis y como un elemento central de la búsqueda de una mejor } \\
\text { vida para las comunidades indígenas." (entr. UNICH-Rector). } \\
\text { "Nosotros estamos firmando un convenio con Cuba para trabajar un proyecto que tiene } \\
\text { que ver con el desarrollo participativo y que no es otra cosa más que impulsar el } \\
\text { desarrollo desde las comunidades con un esquema participativo, integral, incluyente, que } \\
\text { se sienta empoderada la gente de la comunidad en su propio bienestar. Es decir, nosotros }\end{array}$ \\
\hline & $\begin{array}{l}\text { no hemos teorizado tanto sobre el tema, no hay textos concretos, y ahora el proyecto que } \\
\text { estamos arrancando busca precisamente, el primer tema es la discusión teórica del } \\
\text { desarrollo y del buen vivir en las comunidades. Para luego trabajarlo con mayor } \\
\text { sistematización." (entr. UIEM-Rector). }\end{array}$ \\
\hline
\end{tabular}

Tabla 4. Construcción discursiva del Buen Vivir en el discurso institucional en la UNICH y la UIEM (elaboración propia). 
En el discurso de ambos directivos se puede observar que, por un lado, el desarrollo, el Buen Vivir y el "mejor vivir" se consideran básicamente un solo concepto con nombres diferentes, pero por otro lado, se declara que el Buen Vivir y la concepción moderna del desarrollo y progreso son dos cosas distintas, dado que la concepción de la vida buena difiere entre culturas y deriva de necesidades contextuales específicas. Se trata de otro tipo de incoherencia discursiva, ya que no se puede considerar dos conceptos al mismo tiempo compatibles y discrepantes. El Buen Vivir puede ser un referente cada vez más usado en el discurso sobre el bienestar en Latinoamérica, pero en el caso de las Universidades Interculturales en México parece imperar bastante ignorancia acerca de sus posibles significados y acepciones, al fin que ninguno de los rectores ni trabajadores académicos lo supo relacionar con cualquiera de los tres debates dominantes (socialista, ecologista, indigenista) que hoy en día transcurren en torno a este concepto. La tendencia es más bien integrarlo en la noción convencional del crecimiento económico, o sea, "domesticarlo".

Respecto al discurso de los egresados surge la siguiente pregunta: ¿Cómo los exalumnos manejan, reproducen o ajustan las ideas sobre el bienestar recibidas en la Universidad Intercultural? Los alumnos de la UNICH y la UIEM obviamente no son ninguna especie de tabula rasa que pueda simplemente cubrirse con el discurso interculturalista. Traen ideas muy variadas desde antes de ingresar en la Universidad Intercultural, las que dependen de sus experiencias vitales ligadas a los ámbitos de procedencia (ciudad, campo, etc.), características étnicas personales y los diversos factores de personalidad, entre otros.

Sin importar la carrera estudiada 4 , los egresados de la UNICH y la UIEM nos compartían con facilidad sus ideas sobre el bienestar, la calidad de vida y el desarrollo; son los temas centrales del modelo educativo en que se habían formado. El tipo de discurso que utilizan tiene características particulares. Por un lado, manifiestan una significativa confianza en los planteamientos del modelo educativo intercultural respecto al bienestar, sin embargo, esto no significa que resignen a posiciones críticas y no conformistas que incluyen posturas ecologistas, anticonsumistas, filantrópicas, altruistas, etc. Lo relevante es que sus críticas no suelen (con sólo dos excepciones) tocar la base misma del modelo educativo, por ejemplo las discrepancias conceptuales entre el diálogo de saberes y las nociones convencionales del desarrollo centralmente gestionado, tal como aparecen en la teoría educativa. En consecuencia, critican más bien las "malas prácticas" de sus almae matres que a su juicio no permiten practicar el modelo educativo en su plenitud. La problemática se ilustra en la Tabla 5 :

\begin{tabular}{|l|l|}
\hline \multicolumn{2}{|c|}{ La concepción del desarrollo en el discurso de los egresados de la UNICH y la UIEM } \\
\multicolumn{1}{|c|}{$\begin{array}{c}\text { Grado de } \\
\text { identificación }\end{array}$} & \multicolumn{1}{c|}{ Testimonios particulares } \\
\hline $\begin{array}{l}\text { I) Identificación con } \\
\text { la retórica de la } \\
\text { Universidad } \\
\text { Intercultural }\end{array}$ & $\begin{array}{l}\text { "(En la Universidad Intercultural) se pretende que los distintos aportes culturales se } \\
\text { negocien y entren en diálogo con otras perspectivas porque a partir de esa dinámica } \\
\text { podemos pensar socialmente en proyectos que como humanidad nos muestren } \\
\text { distintas alternativas de sociabilidad y una relación diferente hacia el entorno natural, } \\
\text { hacia el trato a la diversidad humana, hacia otras maneras de consumo..." (entr. UIEM- } \\
\text { EG5) } \\
\text { "Ése es uno de los fines de la (Universidad) Intercultural, ser la voz de esas } \\
\text { comunidades que, en ocasiones, cuando llegan a ser escuchadas, es desde un punto } \\
\text { de vista hasta cierto punto "marginal"." (entr. UIEM-EG4) } \\
\text { "La gente de la comunidad sabe de sus tradiciones, tiene ese conocimiento tanto } \\
\text { como nosotros, pero tal vez no sepan cómo desarrollarlo, entonces a nosotros nos } \\
\text { prepara la escuela para hacer estos facilitadores..." (entr. UNICH-EG3) }\end{array}$ \\
\hline
\end{tabular}




\begin{tabular}{|c|c|}
\hline $\begin{array}{l}\text { II) Identificación con } \\
\text { la retórica de la } \\
\text { Universidad } \\
\text { Intercultural } \\
\text { (alumnos de origen } \\
\text { indígena) }\end{array}$ & $\begin{array}{l}\text { "Aunque me gustaría ir a otros municipios y comunidades pero siempre me mandan a } \\
\text { mi pueblo y sí, hay que sacar adelante el municipio. (...) La gente de mi comunidad me } \\
\text { ve algo diferente como de antes, algunos me dicen Licenciado o profesionista, } \\
\text { además me han confiado mucho, a veces me necesitan para hacer unas solicitudes u } \\
\text { oficios que mandan en la presidencia municipal para solicitar apoyo." (entr. UNICH- } \\
\text { EG1-tzotzil) } \\
\text { "(Las Universidades Interculturales) están planteadas por la SEP, entonces yo creo } \\
\text { que ellos en un momento Ilegaron a conocer, a sentir qué es lo que está pasando en } \\
\text { las comunidades indígenas porque realmente sí hay un rezago en cuestiones } \\
\text { educativas y el desarrollo personal es muy bajo. (...) Entonces esta Universidad } \\
\text { Intercultural creo que es una oportunidad para la gente indígena porque no todos } \\
\text { tenemos la oportunidad de entrar a una universidad..." (entr. UNICH-EG10-tzeltal) } \\
\text { (Después de egresar de la UNICH, la gente de mi comunidad) me ven distinto por mi } \\
\text { forma de vestir, hablar, tratar, compartir lo que conozco, algunas veces me piden } \\
\text { apoyo en la gestión de algún proyecto, elaboración de alguna solicitud... (...) Ahora que } \\
\text { tengo la oportunidad de estar trabajando con las mujeres, no es verlas como una } \\
\text { máquina o una trabajadora o una persona que hace dinero sino verse en sí como } \\
\text { personas. Yo creo que hay un futuro mejor para ellas. Porque ellas tienen las niñas, las } \\
\text { jóvenes, ellas como tienen más talento creativo de hacer nuevos diseños, y no sólo } \\
\text { hay el telar de la cintura pero también el telar de pedal. (...) Ya esta semana vamos a } \\
\text { llevar como un curso de inducción del modelo del desarrollo integral." (entr. UNICH- } \\
\text { EG4-tzotzil) }\end{array}$ \\
\hline $\begin{array}{l}\text { III) Crítica de las } \\
\text { "malas prácticas" en } \\
\text { las Universidades } \\
\text { Interculturales }\end{array}$ & $\begin{array}{l}\text { "Creo que el enfoque de la Uni está mal, muy mal, se iluminan la boca de que } \\
\text { ayudamos a los indígenas cuando no es así. Deberían hacer proyectos reales, } \\
\text { empezar y terminar o dejarlos en seguimiento con los miembros de la comunidad, } \\
\text { investigaciones que sirvan, que tengan resultados, que se bajen recursos y que no se } \\
\text { pierdan en el camino, que se vea la ayuda comunitaria. (..) Me gustaría súper poner en } \\
\text { práctica mi trabajo comunitario... ver que una comunidad mejora con mi ayuda, que } \\
\text { pueda hacer un poco por la gente que necesita, atender sus peticiones, hacer } \\
\text { proyectos juntos y sacarlos adelante." (entr. UIEM-EG10) } \\
\text { "Me percaté que ese enfoque "intercultural" solo lo lleva el nombre de la Universidad } \\
\text { porque también existe el clasismo, y mis perspectivas que tenía yo eran diferentes, ya } \\
\text { que consideraba la interculturalidad ese vínculo de la carrera para que fuese de ayuda } \\
\text { con la comunidad y no fue tanto así." (entr. UIEM-EG8) }\end{array}$ \\
\hline $\begin{array}{l}\text { IV) Críticas de la } \\
\text { idea de "desarrollo" } \\
\text { en el modelo } \\
\text { educativo de la } \\
\text { Universidad }\end{array}$ & $\begin{array}{l}\text { "He visitado a los zapatistas pero creo firmemente que es necesario hacer algo aquí } \\
\text { (en el Estado de México) también, aprendemos mucho de ellos. (...) Espero poder dejar } \\
\text { de depender de los centros comerciales, espero que mucha gente se interese por } \\
\text { sembrar su verdura, por ya no consumir tanto, espero ser un ejemplo..." (entr. UIEM- } \\
\text { EG6) }\end{array}$ \\
\hline Intercultural & $\begin{array}{l}\text { "Confrontar el mismo conocimiento, es decir, cómo lograr hacer epistemología desde } \\
\text { lo local, de esa diversidad para lograr estos modelos alternativos de vidas ideales, } \\
\text { para no llamarlo desarrollo. (...)El concepto de la calidad de vida era clave en todas las } \\
\text { teorías del desarrollo local. ¿Sabrán de esto las comunidades, de la calidad de vida? } \\
\text { ¿Cómo se está entendiendo? ¿Está confrontado con el Buen Vivir?" (entr. UNICH-EG7) }\end{array}$ \\
\hline
\end{tabular}

Tabla 5. La concepción del bienestar y desarrollo en el discurso de los egresados de la UNICH y la UIEM (elaboración propia). 
Esta cuestión se hace particularmente interesante al analizar los testimonios de los egresados que son hablantes maternos de lenguas originarias y se consideran miembros de un pueblo indígena. Varios egresados con estas características, hablantes de tzotzil y tzeltal, avalan el carácter compensatorio de la Universidad Intercultural, interpretándolo como una oportunidad nueva para los jóvenes de origen indígena. Sin embargo, también dejan testimonios de que la formación recibida en la Universidad Intercultural los ha transformado en agentes de cambio y en consecuencia, en las comunidades de origen se han convertido en personas respetadas y al mismo tiempo de cierto modo enajenadas de la vida comunitaria tradicional. De tal modo que estos jóvenes licenciados han pasado a ser una especie de intermediarios entre el mundo comunitario y el mundo "afuera"; traen el espíritu de innovación y de competencia que puede evidenciarse por ejemplo en la mención de la necesidad de "modernizar" los modelos tradicionales de la vestimenta tzotzil para fines de venta (véase el punto II de la Tabla 5).

En síntesis, igual que en el caso de los trabajadores de la UNICH y la UIEM, la identificación de los egresados con los lineamientos axiológicos de la Universidad Intercultural es bastante alta.

\section{Conclusiones}

A lo largo del presente texto se ha demostrado que en general existe una notable coherencia argumentativa dentro del discurso dedicado a la problemática del bienestar y desarrollo, tanto en la teoría educativa de la Universidad Intercultural como en los testimonios personales provenientes de la UNICH y la UIEM. Dicho de otro modo, la visión que los actores institucionales tienen acerca de estos temas es muy parecida a la expuesta en el manual del modelo educativo. Si varía, es principalmente por el grado de idealización oficialista. Ésta es bastante marcada en la retórica de los rectores, contrasta con las visiones más sobrias y realistas de los trabajadores del área de la Vinculación Comunitaria quienes se mueven en las prácticas de campo cotidianas, y aún más con las de los egresados, profesionistas de corte nuevo y alternativo. El lenguaje conceptual en torno al bienestar es muy semejante entre todos ellos y en esencia compromete a los grupos culturalmente minoritarios, vistos como rezagados, con la superación de sus condiciones de vida actuales bajo el prisma individualista occidental, resumido en el término "desarrollo". La condición étnica (indígena/no indígena) de los actores no parece ser una variable que transforme considerablemente este tipo de discurso.

El uso de conceptos que se alejen del lenguaje económico dominante es más bien escaso. La categoría alternativa más usada es la del Buen Vivir, posiblemente debido a la necesidad de participar en este debate actual que concierne a los que trabajan la problemática de la interculturalidad latinoamericana. Sin embargo, en la concepción de los actores institucionales, el Buen Vivir se relaciona básicamente con las diferentes necesidades que hay que atender en cada localidad, de modo que los conceptos "desarrollo" y "Buen Vivir" llegan a fundirse en uno solo en el flujo discursivo. Lo anterior sin apoyarse de manera fundamentada en alguno de los debates abiertos sobre el Buen Vivir, lo cual convierte los discursos analizados en un componente más de la estrategia oficial del Estado usada para canalizar las minorías étnicas hacia las metas establecidas desde el sistema valorativo moderno.

En lo que concierne la teoría educativa de la Universidad Intercultural como un todo, resulta que las ideas convencionales acerca del desarrollo dificultan la meta explícita del modelo educativo que consiste en dialogar con los miembros de otros grupos culturales en condiciones de igualdad epistémica. Obviamente, esta limitación no significa que el modelo educativo no sea capaz de traer resultados positivos a las poblaciones indígenas atendidas. Lo que pretendemos señalar es más bien el hecho de que, en la práctica, el proclamado derecho de los pueblos indígenas a una educación culturalmente pertinente se ve privado de un componente importante: al menos a nivel de los tres tipos del discurso recolectado, parece inverosímil que los pueblos indígenas puedan codecidir qué tipo de educación y desarrollo consideran adecuado para sus localidades. En consecuencia, las Universidades Interculturales tratan a las comunidades indígenas principalmente como los atendidos, sólo secundariamente como los consultores y nunca como los gestores. 


\section{Bibliografía}

Acosta, A. (2014): "El Buen Vivir: más allá del desarrollo", en G. C. Delgado Ramos, ed., Buena vida, buen vivir: Imaginarios alternativos para el bien común de la humanidad, México, UNAM, pp. 21-60.

Acosta, A. (2013): El Buen Vivir. Sumak Kawsay, una oportunidad para imaginar otros mundos, Barcelona, Icaria.

Casillas Muñoz, M. y Santini Villar, L. (2006): Universidad intercultural: un modelo educativo, México, SEP.

Dourojeanni, A. (1999): "La dinámica del desarrollo sustentable y sostenible", documento del XV Congreso Venezolano de la Ciencia del Suelo, CEPAL. Disponible en web http://repositorio.cepal. org/bitstream/handle/11362/19862/S9970510_ es.pdf?sequence $=1 \&$ isAllowed=y [Consulta: 16 de marzo de 2017]

Escobar, A. (1992): "Imagining a Post-Development era? Critical Thought, Development and Social Movements", Social Text, 31/32, p. 30-56.

Hidalgo-Capitán, A. L. (2014): Seis debates abiertos sobre el sumak kawsay, Íconos (48), pp. 25-40.

Huanacuni Mamani, F. (2010): Buen Vivir / Vivir Bien. Filosofía, políticas, estrategias y experiencias regionales andinas, Lima, Coordinadora Andina de Organizaciones Indígenas.

Korsbaek, L. y Sámano Rentería, M. A. (2007): "El indigenismo en México. Antecedentes y actualidad", Ra Ximhai, 1 (3), pp. 195-224.

Leff, E. (2000): Los problemas del conocimiento y la perspectiva ambiental del desarrollo, México, Siglo XXI.

Leff, E. (2000a): Saber Ambiental. Sustentabilidad, racionalidad, complejidad, poder, México, PNUMA, Siglo XXI.

Mato, D. (2014): "Universidades Indígenas en América Latina. Experiencias, logros, problemas, conflictos y desafíos", ISEES, 14, pp. 17-45.

Mato, D. (2009, coord.): Instituciones interculturales de educación superior en América Latina. Procesos de construcción, logros, innovaciones y desafíos, Caracas, IESALC-UNESCO.

Nederveen Pieterse, J. (2001). Development Theory. Deconstructions/ Reconstructions, Gran Bretaña, Sage Publications.

Nijkamp, P., van den Bergh, C. J. M. y Soeteman, F. (1990): "Regional Sustainable Development and Natural Resource Use", The World Bank Annual Conference on Development Economics. Recuperado de http://documents.worldbank.org/curated/en/ 239311468771020043/pdf/multi-page.pdf [Consulta: 16 de marzo de 2017]
Organización de las Naciones Unidas (1987): "Informe de la Comisión Mundial sobre el Medio Ambiente y el Desarrollo, Anexo: "Nuestro futuro Común", en J. Rawls, ed., 1985, Teoría de la justicia, México, Fondo de Cultura Económica.

Peet, R. \& Hartwick, E. (2009): Theories of Development, USA: The Guilford Press.

Sartorello, S. C., Ávila, L. E. y Ávila, A. (2012): El Buen Vivir: Miradas desde adentro de Chiapas, San Cristóbal de Las Casas, Editorial Fray Bartolomé de Las Casas.

Rawls, J. (1985, ed.): Teoría de la justicia, México, Fondo de Cultura Económica.

Sen, K. A. (1983): "Los bienes y la gente", Revista de Comercio Exterior, Especial de Aniversario II (50), septiembre 2000, pp. 1115-1123.

Soler García, C., Caballero Segarra E. \& Nogués Pedregal, A. (2014): Conversatorio sobre interculturalidad y desarrollo, Murcia, Cantera editorial.

Vargas-Moreno, P. (2016): Educación Superior Intercultural en Ecuador y México. Disputas y tendencias. Revista del Cisen Tramas/Maepova, 4 (2), pp. 121-142.

Recibido 16 de marzo de 2017. Aceptado: 7 de julio de 2017

\section{Notas}

1 El artículo desprende del proyecto de investigación titulado "La Universidad Intercultural como un fenómeno multidimensional: una perspectiva desde México", Facultad de Humanidades, Universidad Autónoma del Estado de México, 2012-2015.

2 Entre los enfoques que han caracterizado los nuevos discursos del desarrollo se ubican los siguientes: el postdesarrollismo (Escobar, 1992), el desarrollo humano (Rawls, 1985; Sen, 1983), el desarrollo sustentable (ONU, 1987; Dourojeanni, 1999; Nijkamp et al., 1990), el eco-desarrollo (Leff 2000; 2000a) y las nociones indígenas del Buen Vivir (Huanacuni, 2010; Acosta, 2013), entre otros

3 Esta concepción prescinde ciertas nociones políticamente inconvenientes, como es el contexto de poder en que se enmarca la relación entre el Estado y los pueblos originarios en México.

$4 \quad$ Los entrevistados se formaron en el marco de las siguientes licenciaturas: Turismo Alternativo (UNICH), Desarrollo Sustentable (UNICH, UIEM), Comunicación Intercultural (UNICH, UIEM) y Lengua y Cultura (UIEM). 